\section{Psychological Medicine}

cambridge.org/psm

\section{Original Article}

Cite this article: Harris MA et al (2020). Stratifying major depressive disorder by polygenic risk for schizophrenia in relation to structural brain measures. Psychological Medicine 50, 1653-1662. https://doi.org/ 10.1017/S003329171900165X

Received: 11 September 2018

Revised: 28 May 2019

Accepted: 19 June 2019

First published online: 18 July 2019

\section{Key words:}

Cortical thickness; fractional anisotropy; heterogeneity; major depressive disorder; polygenic risk; schizophrenia; subtypes

Author for correspondence:

Mathew A. Harris, E-mail: mat.harris@ed.ac.uk

\section{Stratifying major depressive disorder by polygenic risk for schizophrenia in relation to structural brain measures}

Mathew A. Harris ${ }^{1}\left(\mathbb{D}\right.$, Xueyi Shen ${ }^{1}\left(\mathbb{D}\right.$, Simon R. Cox $^{2,3}\left(\mathbb{D}\right.$, Jude Gibson ${ }^{1}$ (D), Mark J. Adams ${ }^{1}(\mathbb{D})$, Toni-Kim Clarke ${ }^{1}$ (D) Ian J. Deary ${ }^{2,3}$ (D), Stephen M. Lawrie ${ }^{1}$ (D), Andrew M. Mclntosh ${ }^{1,3}$ (D) and Heather C. Whalley ${ }^{1}$ (D)

${ }^{1}$ Division of Psychiatry, University of Edinburgh, Edinburgh, UK; ${ }^{2}$ Department of Psychology, University of Edinburgh, Edinburgh, UK and ${ }^{3}$ Centre for Cognitive Ageing and Cognitive Epidemiology, University of Edinburgh, Edinburgh, UK

\begin{abstract}
Background. Substantial clinical heterogeneity of major depressive disorder (MDD) suggests it may group together individuals with diverse aetiologies. Identifying distinct subtypes should lead to more effective diagnosis and treatment, while providing more useful targets for further research. Genetic and clinical overlap between MDD and schizophrenia (SCZ) suggests an MDD subtype may share underlying mechanisms with SCZ.

Methods. The present study investigated whether a neurobiologically distinct subtype of MDD could be identified by SCZ polygenic risk score (PRS). We explored interactive effects between SCZ PRS and MDD case/control status on a range of cortical, subcortical and white matter metrics among 2370 male and 2574 female UK Biobank participants.

Results. There was a significant SCZ PRS by MDD interaction for rostral anterior cingulate cortex (RACC) thickness $(\beta=0.191, q=0.043)$. This was driven by a positive association between SCZ PRS and RACC thickness among MDD cases $(\beta=0.098, p=0.026)$, compared to a negative association among controls $(\beta=-0.087, p=0.002)$. MDD cases with low SCZ PRS showed thinner RACC, although the opposite difference for high-SCZ-PRS cases was not significant. There were nominal interactions for other brain metrics, but none remained significant after correcting for multiple comparisons.

Conclusions. Our significant results indicate that MDD case-control differences in RACC thickness vary as a function of SCZ PRS. Although this was not the case for most other brain measures assessed, our specific findings still provide some further evidence that MDD in the presence of high genetic risk for SCZ is subtly neurobiologically distinct from MDD in general.
\end{abstract}

(c) Cambridge University Press 2019. This is an Open Access article, distributed under the terms of the Creative Commons Attribution licence (http://creativecommons.org/licenses/ by/4.0/), which permits unrestricted re-use, distribution, and reproduction in any medium, provided the original work is properly cited.

\section{CAMBRIDGE} UNIVERSITY PRESS
Major depressive disorder (MDD) is a prevalent and frequently disabling psychiatric disorder, associated with prolonged low mood, although many unique symptom combinations may lead to the same diagnosis (Gallo and Rabins, 1999; Kennedy, 2008). The high clinical heterogeneity suggests that MDD may group together a number of disease subtypes (Fava et al., 1997; Baumeister and Parker, 2012; van Loo et al., 2014). Differences in clinical presentation may reflect differences in aetiology and underlying neurobiological mechanisms. Identifying subtypes of MDD is therefore likely to be a crucial step toward more effective diagnosis and treatment of affected individuals, as well as providing better targets for genomic and neurobiological studies.

The heritability of MDD is estimated to be about 37\% (Sullivan et al., 2000), determined by a large number of alleles each of small effect (Ripke et al., 2013). MDD subtypes may differ in terms of which alleles (Flint and Kendler, 2014) and which biological mechanisms (Hasler et al., 2004) are involved. For example, Milaneschi et al. (2017) demonstrated only a very small genetic overlap between typical MDD (associated with decreased appetite and weight) and an atypical subtype (associated with increased appetite and weight). Focusing more specifically on stratifying MDD by genetic factors, Howard et al. (2017) recently identified 10 variables related to genetic subgroups that might partly account for the heterogeneity of MDD. Further investigation of specific genetic subgroups may help to identify more clinically and empirically useful MDD subtypes.

Some genes that contribute to MDD overlap with those underlying schizophrenia (SCZ; Schulze et al., 2014) and the two disorders have a genetic correlation of $r_{\mathrm{g}}=0.43$ (Cross-Disorder Group of the Psychiatric Genetics Consortium et al., 2013). Individuals with MDD also at high polygenic risk of SCZ have been previously shown to differ in terms of clinical and behavioural phenotypes. Whalley et al. (2016) observed higher 
neuroticism and psychological distress among controls with a higher SCZ polygenic risk score (PRS), but not among high-SCZ-PRS MDD cases. Additionally, Power et al. (2017) found that MDD subtypes based on age of onset differed in terms of SCZ PRS, and early-onset cases have been found to show greater deficits in frontal (Jaworska et al., 2014) and limbic (MacMaster et al., 2008; Clark et al., 2018) regions. This may suggest a different aetiology and perhaps different neurobiological profile of MDD in the presence of high genetic risk for SCZ, i.e. an SCZ-risk-related MDD subtype. It seems that some of the genes that may contribute to both SCZ and MDD are involved in regulating synaptic function and the excitability of prefrontal neurons (Howard et al., 2019). However, whether subtypes of MDD based on genetic loading for SCZ are distinct in terms of brain structure has yet to be determined.

MDD is typically associated with fronto-limbic deficits, including reduced cortical volume/thickness in prefrontal regions (Salvadore et al., 2011; Rodriguez-Cano et al., 2014; Schmaal et al., 2017), and smaller subcortical limbic structures (Kim et al., 2008; Lu et al., 2016; Schmaal et al., 2016). Reductions in integrity of connecting white matter tracts have also been observed (Cole et al., 2012; Bessette et al., 2014; Shen et al., 2017). Fronto-limbic impairments are also apparent in SCZ (Ross et al., 2006; Keshavan et al., 2008; Yao et al., 2013), along with more widespread white matter deficits (Ellison-Wright and Bullmore, 2009) and greater cortical reductions in temporal regions (Wong and van Tol, 2003). Furthermore, some SCZ-like neuroimaging markers, such as reduced hippocampal, thalamic and prefrontal volumes, appear in individuals who are genetically predisposed to SCZ but remain healthy (Lawrie et al., 2001; Boos et al., 2007). As of yet, the influences of SCZ risk on such neurobiological measures in the presence of MDD are unclear.

Following on from previous work stratifying MDD traits by PRS for SCZ (Whalley et al., 2016), we aimed to measure the neuroimaging associations of MDD as a function of SCZ PRS, testing for further evidence of MDD subtype heterogeneity related to SCZ risk. We assessed interactive effects between SCZ PRS and MDD case/control status on measures of cortical, subcortical and white matter structure. Based on previous evidence of neuroimaging abnormalities in healthy subjects at high genetic risk for SCZ (Lawrie et al., 2001; Boos et al., 2007), we expected negative correlations between SCZ PRS and brain measures among both cases and controls, with significant interactions between MDD and SCZ PRS indicating a specific subtype. Without any specific hypotheses regarding the neurobiological bases of differences in neuroticism and distress among high-SCZ-risk MDD cases, we took an exploratory approach, testing SCZ PRS by MDD interactions for structural measures covering the entire brain. We did, however, anticipate interactions in areas that normally show deficits in MDD, such as frontal cortical regions, limbic structures and connecting white matter tracts. Any significant interactions, indicating that MDD's associations with neuroimaging measures differed as a function of SCZ PRS, would provide evidence of an SCZ-risk-related MDD subtype.

\section{Methods \\ Participants}

Data were derived from 4944 participants in the large-scale prospective epidemiological study, UK Biobank (http://www/ ukbiobank.ac.uk). UK Biobank includes data on 503325 members of the general UK population, recruited between 2006 and 2010 (Allen et al., 2012). Participants originally provided information on a wide range of health, lifestyle, environment and other variables, and the majority have also provided genetic data. The project aims to submit approximately 100000 of the participants to a full-body imaging protocol, which includes the acquisition of neuroimaging data in several modalities (Miller et al., 2016). The present study focused on 4944 UK Biobank participants for whom both genetic and brain imaging data have already been acquired, who also had data on MDD and relevant covariates, described below. Participants who reported a diagnosis of schizophrenia were excluded from all analyses. Descriptive statistics for included participants are reported in Table 1.

\section{Polygenic risk for schizophrenia}

UK Biobank blood samples were genotyped using either the UK BiLEVE array or UK Biobank Axiom array, and quality controlled at the Wellcome Trust Centre for Human Genetics (Wain et al., 2015; Hagenaars et al., 2016). Further quality control measures included removal of participants based on missingness, relatedness, non-British ancestry and gender mismatch. Subsequent processing involved removal of SNPs with minor allele frequency $<1 \%$, and clump-based linkage disequilibrium pruning $\left(r^{2}<0.25\right.$ within a $200 \mathrm{bp}$ window). PRSs for SCZ were calculated for each participant using PRSice (Euesden et al., 2015) and genomewide association study summary data (Schizophrenia Working Group of the Psychiatric Genetics Consortium, 2014), including SNPs selected according to the significance of their associations with the phenotype at thresholds of $p<0.01, p<0.05, p<0.10$, $p<0.50$ and all SNPs.

\section{Major depressive disorder}

As part of a web-based mental health questionnaire, UK Biobank participants completed the short form of the Composite International Diagnostic Interview (CIDI-SF; Kessler et al., 1998). Section A of the CIDI-SF focuses on MDD symptomatology, providing a score of between zero and eight. Participants with a score of five or more were classified as lifelong MDD cases; those with a score of four or less as controls. Participants who scored highly but did not report having experienced core symptoms of either low mood or anhedonia were excluded. CIDI-SF controls who had previously reported a past diagnosis of depression or showed signs of MDD on the 9-item Patient Health Questionnaire (PHQ-9; Kroenke et al., 2001) were also excluded $(N=286)$. The resulting CIDI-assessed measure of MDD therefore included 1674 cases and 3270 controls (Table 1). Some of the earlier scanned subjects completed the web-based questionnaire up to 2.7 years later, but most completed it within a year of imaging data acquisition.

\section{Brain imaging data}

Full information on imaging data acquisition and processing are provided in supplementary materials and previous publications (Miller et al., 2016; Alfaro-Almagro et al., 2018). To summarise, all structural and diffusion data were acquired on the same $3 \mathrm{~T}$ scanner using the same protocol. Cortical metrics for 27 regions $(N=1877)$ were derived locally using FreeSurfer version 5.3 (Dale et al., 1999; Fischl et al., 1999, 2004; Desikan et al., 2006). Volumes of seven subcortical structures $(N=4944)$ were 
Table 1. Descriptive statistics for MDD cases and controls, and group differences

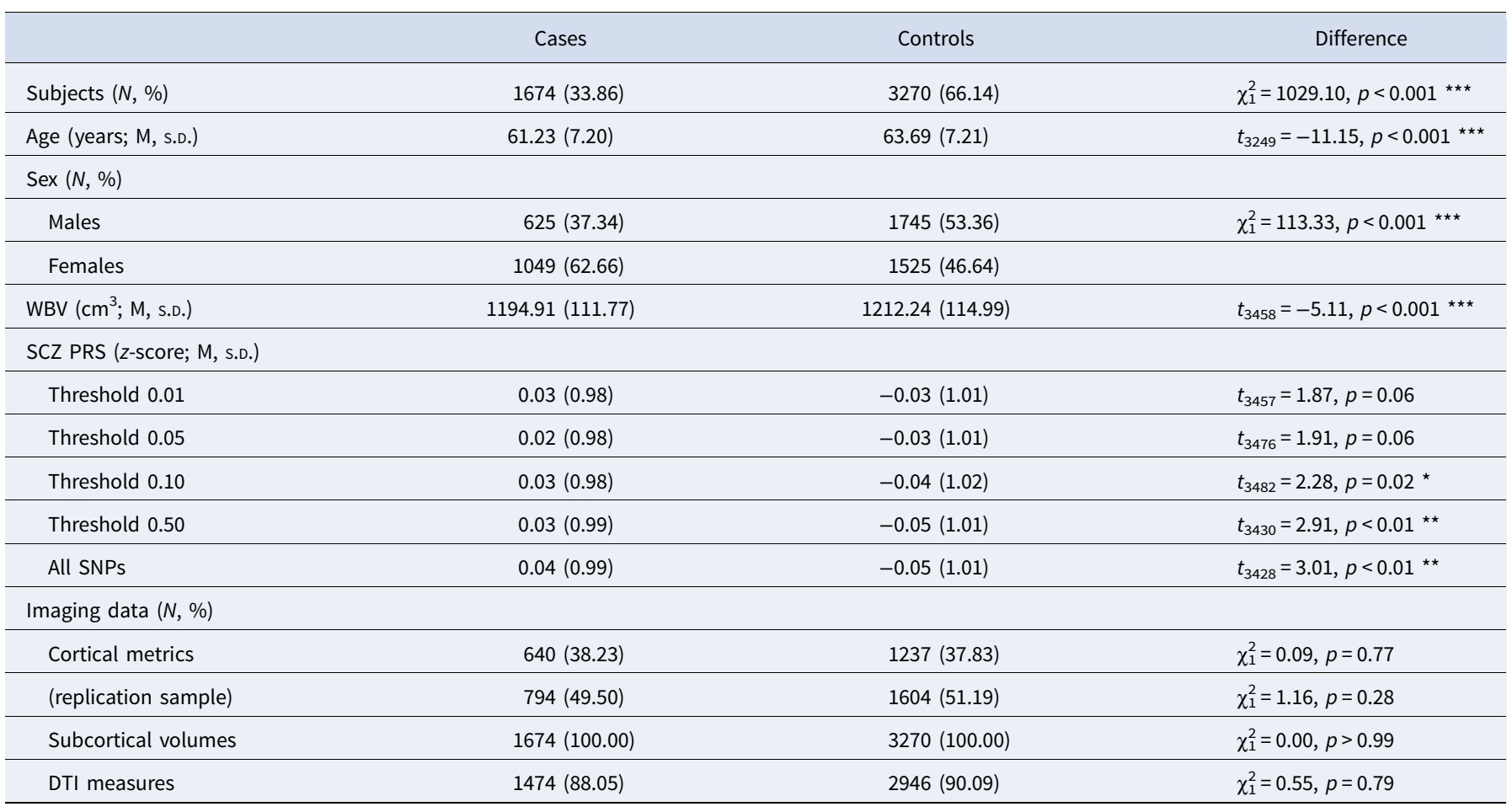

MDD, major depressive disorder; WBV, whole brain volume; SCZ, schizophrenia; PRS, polygenic risk score; DTI, diffusion tensor imaging.

Group differences were assessed using $\chi^{2}$ tests and two-sample $t$ tests.

${ }^{\star},{ }^{\star \star}$ and ${ }^{\star \star \star}$ represent significant results at $p<0.05, p<0.01$ and $p<0.001$, respectively

derived by the UK Biobank imaging team using FIRST (Patenaude et al., 2011). Fractional anisotropy (FA) and mean diffusivity (MD) of 15 white matter tracts $(N=4420)$ were also derived by the UK Biobank imaging team using bedpostx and probtrackx (Behrens et al., 2007), and then AutoPtx (de Groot et al., 2013).

At the time of beginning this study, subcortical volumes and white matter metrics were available for the first two releases of UK Biobank imaging data, while cortical metrics were available for only the first release. Following initial submission of our results for publication, cortical metrics became available for the second release as well, including for 794 MDD cases and 1604 controls who met the criteria for inclusion in this study. We have therefore used these additional data to replicate any significant findings discovered in the first release.

\section{Additional covariates}

In relation to SCZ PRS, genotyping array and the first 15 ancestry principal components (controlling for population stratification within the sample) were included as covariates in all analyses. We used as many as 15 principal components to control for the substantial genetic clustering recently found in UK Biobank (Abdellaoui et al., 2018). Including more than 15 made negligible difference to our results. In relation to neuroimaging data, $x, y$ and $z$ coordinates of head position within the MRI scanner were included as covariates, along with a measure of whole-brain volume (including grey matter, white matter and ventricles), derived from the UK Biobank image processing pipeline (Alfaro-Almagro et al., 2018). Additionally, age in years at time of scanning, age ${ }^{2}$ and sex were included in all analyses.

\section{Statistical analysis}

Data were analysed in $\mathrm{R}$ version 3.2.3 ( $\mathrm{R}$ Core Team, 2013). As additional quality control, outliers, defined as further than three standard deviations from the mean, were removed from all neuroimaging measures. Left and right measures were then combined bilaterally, as above; a general lack of hemispheric effects in the same UK Biobank subcortical and white matter phenotypes has been reported previously (Shen et al., 2017). We performed analyses of case-control differences in group size, sex and SCZ PRS, reported in Table 1. For each regional brain measure and each PRS threshold, we then ran linear regression models to estimate the strength of the interactive effect between SCZ PRS and MDD in all participants, controlling for the main effects of each, as well as effects of age, age ${ }^{2}$, genotyping array, the first 15 principal components of genetic ancestry, whole-brain volume and scanner head position coordinates. FDR correction was applied to $p$ values across all interaction effects together.

As main effects of SCZ PRS among MDD cases would not demonstrate whether the effects were specific to cases, only interactions between MDD and SCZ PRS could provide indications of aetiological differences between MDD cases at high and low SCZ risk. However, where interactions were significant, we assessed main effects of SCZ PRS among MDD cases and controls separately, and tested case-control differences among those above and below mean SCZ PRS. Together, these analyses provided further information on how MDD and SCZ risk interact. We additionally tested whether significant interactions were influenced by a subgroup of MDD cases with both repeated k-mean and hierarchical cluster analyses, using package 'fpc' (Henning, 2015) in addition to base packages. Further packages 'ggplot2' (Wickham and Chang, 2016) and 'ellipse' (Murdoch and Chow, 2013) were 
also used to create figures. Results are reported in terms of standardised $\beta$ coefficients, and $\mathrm{p}$ values and $\mathrm{q}$ values (FDR-corrected $\mathrm{p}$ values) $<0.05$ are considered significant.

\section{Results}

Descriptive statistics are reported for MDD cases and controls in Table 1. MDD cases were younger than controls $\left(t_{3252}=-11.15\right.$, $p<0.001)$, a higher proportion of cases were female $\left(\chi_{1}^{2}=113.33\right.$, $p<0.001)$, and WBV was lower among cases $\left(t_{3460}=5.11, p<\right.$ $0.001)$. These variables were controlled in all subsequent analyses. Mean PRS was slightly higher among cases at thresholds 0.10 $\left(t_{3484}=2.28, p=0.02\right), 0.50\left(t_{3430}=2.91, p<0.01\right)$ and all SNPs $\left(t_{3427}=3.01, p<0.01\right)$. All SCZ PRS by MDD interactions tested for both MDD measures are summarised in Fig. 1; within each measure, fronto-limbic areas are presented first.

\section{Cortical regions}

Analyses of cortical metrics focused on a subset of 1877 subjects for whom these data were available. We first assessed interactive effects between SCZ PRS and MDD on regional mean cortical thickness. There were significant interactive effects across multiple PRS thresholds of at least $\beta=0.132(p=0.009)$ in rostral ACC, $\beta=0.101(p=0.042)$ in superior temporal gyrus and $\beta=0.120$ $(p=0.037)$ in entorhinal cortex (Table 2). The interaction in rostral ACC was significant across all thresholds and the two strongest of these effects remained significant after FDR correction: for PRS threshold $0.50(\beta=0.191, q=0.043)$ and for all SNPs $(\beta=0.191, q=0.043)$. These interactions were driven by significant negative effects of $\beta=-0.094(p=0.001)$ and $\beta=-0.090$ ( $p=0.002$ ) among controls, but positive effects of $\beta=0.103$ ( $p=$ $0.017)$ and $\beta=0.109(p=0.013)$ among cases. These results mean that greater SCZ PRS was associated with thinner rostral ACC in controls, but not in MDD cases (Fig. 2). Paired $t$ tests confirmed that the case-control difference was significant at PRS thresholds $0.05\left(t_{111}=2.590, p=0.011\right)$ and $0.50\left(t_{111}=2.289, p=0.024\right)$ among those of below-average SCZ PRS, but not at any threshold for those of above-average SCZ PRS.

Given the specific effect of SCZ PRS on rostral ACC mean thickness among MDD cases, we tested whether it was influenced by a subgroup of participants. Repeated k-means clustering of SCZ PRS and rostral ACC thickness data using the function 'pamk' identified three as the optimum (according to average silhouette width; also verified using hierarchical clustering) for each of the three thresholds showing significant interactions. However, as shown in online Supplementary Fig. S1, for each threshold, none of the three clusters clearly represented a high-SCZ-risk subgroup, and none was significantly distinct from the other two, with low Dunn indices (DIs) of 0.009 .

As more cortical data became available later, we were able to retest the interaction between SCZ PRS and MDD on rostral ACC thickness in a replication sample. The interaction was weaker but significant for SCZ PRS thresholds $0.05(\beta=0.095, p=0.024)$ and 0.10 $(\beta=0.083, p=0.047)$. As shown in online Supplementary Fig. S2, the interaction was attenuated mainly by the controls of the replication sample, among whom the negative association between SCZ PRS and rostral ACC thickness was much closer to zero than in the discovery sample $(\beta=-0.013, p=0.595 ; \beta=-0.009, p=$ $0.724)$. The association among MDD cases of the replication sample was still positive, but also weaker than in the discovery sample and no longer significant $(\beta=0.065, p=0.074 ; \beta=0.057, p=0.116)$.

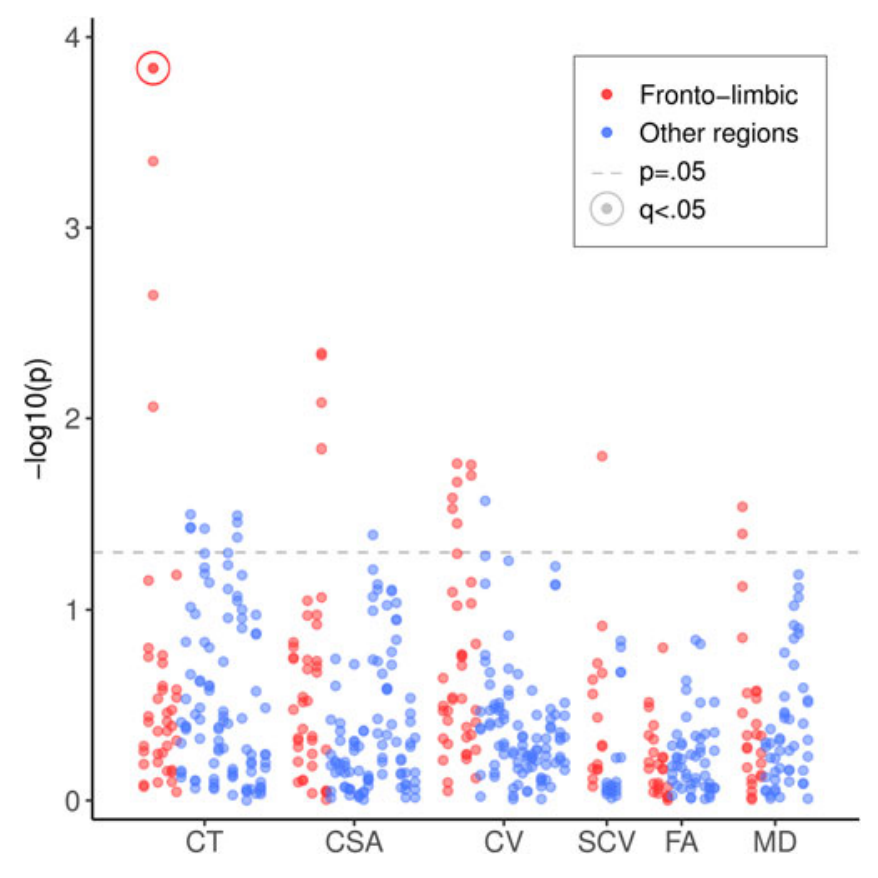

Fig. 1. Significance of SCZ PRS by MDD interactions on all cortical, subcortical and white matter metrics. SCZ, schizophrenia; PRS, polygenic risk score; MDD, major depressive disorder; CT, cortical thickness; CSA, cortical surface area; CV, cortical volume; SCV, subcortical volume; FA, fractional anisotropy; MD, mean diffusivity. Results for fronto-limbic brain regions are presented first in red/darker grey, followed by all other brain regions in blue/lighter grey. Points above the lower dashed line represent results that were significant before correcting for multiple comparisons $(p<0.05)$ Points representing significant results after FDR correction $(q<0.05)$ are circled.

For cortical surface area, there were significant interactions across multiple PRS thresholds of $\beta=-0.091 \quad(p=0.014)$ to $\beta=-0.105(p=0.005)$ in inferior frontal gyrus (IFG), again due to a stronger negative effect of SCZ PRS among MDD cases than controls, but these results failed to survive FDR correction. Full results are reported in online Supplementary Table S1. For cortical volume, there were significant interactions across multiple PRS thresholds of $\beta=-0.088(p=0.020)$ and $\beta=-0.090$ $(p=0.017) \quad$ for IFG, $\beta=0.091 \quad(p=0.029) \quad$ and $\beta=0.094$ $(p=0.026)$ for rostral ACC; and $\beta=0.098 \quad(p=0.035)$ to $\beta=0.110(p=0.017)$ for caudal ACC. However, following FDR correction, none of these interactive effects on regional cortical volumes remained significant (online Supplementary Table S2).

\section{Subcortical structures}

We next tested interactive effects on subcortical volumes, which were available for all 4944 subjects. Across all subcortical volumes and PRS thresholds, there was only one significant SCZ PRS by MDD interaction: a weak positive interactive effect of $\beta=0.047$ $(p=0.016)$ on thalamic volume at PRS threshold 0.01 (online Supplementary Table S3). This was driven by weak and nonsignificant but opposite associations between SCZ PRS and thalamic volume in MDD cases $(\beta=0.030)$ and controls $(\beta=-0.022)$, but the interaction did not remain significant after FDR correction.

\section{White matter tracts}

Finally, we explored interactions in white matter tracts for the 4420 subjects with DTI data. There were no significant interactive 
Table 2. Interactive effects between SCZ PRS and MDD status on mean cortical thickness by region

\begin{tabular}{|c|c|c|c|c|c|c|c|c|c|c|c|c|c|c|c|}
\hline & \multicolumn{3}{|c|}{ PRS threshold 0.01} & \multicolumn{3}{|c|}{ PRS threshold 0.05} & \multicolumn{3}{|c|}{ PRS threshold 0.10} & \multicolumn{3}{|c|}{ PRS threshold 0.50} & \multicolumn{3}{|c|}{ PRS all SNPs } \\
\hline & $\beta$ & S.E. & $p$ & $\beta$ & S.E. & $p$ & $\beta$ & S.E. & $p$ & $\beta$ & S.E. & $p$ & $\beta$ & S.E. & $p$ \\
\hline Dorsolateral PFC & 0.052 & 0.046 & 0.263 & 0.027 & 0.046 & 0.563 & 0.054 & 0.047 & 0.251 & 0.063 & 0.046 & 0.173 & 0.061 & 0.046 & 0.190 \\
\hline Caudal MFG & 0.043 & 0.046 & 0.347 & 0.018 & 0.046 & 0.703 & 0.041 & 0.047 & 0.386 & 0.036 & 0.046 & 0.433 & 0.030 & 0.046 & 0.518 \\
\hline IFG & 0.039 & 0.047 & 0.408 & 0.012 & 0.047 & 0.798 & 0.046 & 0.047 & 0.335 & 0.017 & 0.047 & 0.710 & 0.018 & 0.047 & 0.694 \\
\hline Lateral OFC & 0.032 & 0.049 & 0.519 & 0.023 & 0.050 & 0.646 & 0.030 & 0.050 & 0.553 & 0.010 & 0.050 & 0.848 & 0.011 & 0.050 & 0.830 \\
\hline Medial OFC & 0.093 & 0.051 & 0.070 & 0.047 & 0.052 & 0.363 & 0.045 & 0.052 & 0.387 & 0.073 & 0.052 & 0.159 & 0.070 & 0.052 & 0.176 \\
\hline Frontal pole & 0.091 & 0.049 & 0.066 & 0.006 & 0.050 & 0.902 & 0.035 & 0.050 & 0.486 & 0.055 & 0.049 & 0.262 & 0.053 & 0.050 & 0.289 \\
\hline Rostral ACC & 0.132 & 0.050 & $0.009^{\star \star}$ & 0.154 & 0.050 & $0.002^{\star \star}$ & 0.179 & 0.051 & $<0.001^{\star \star \star}$ & 0.191 & 0.050 & $<0.001^{\star \star \star}$ & 0.191 & 0.050 & $<0.001^{\star \star \star}$ \\
\hline Caudal ACC & 0.050 & 0.048 & 0.293 & 0.038 & 0.048 & 0.434 & 0.028 & 0.049 & 0.570 & 0.023 & 0.048 & 0.630 & 0.012 & 0.048 & 0.805 \\
\hline Posterior cingulate & -0.032 & 0.048 & 0.501 & -0.042 & 0.048 & 0.389 & -0.019 & 0.049 & 0.700 & -0.017 & 0.048 & 0.718 & -0.015 & 0.048 & 0.756 \\
\hline Isthmus cingulate & -0.040 & 0.048 & 0.408 & -0.070 & 0.048 & 0.147 & -0.040 & 0.049 & 0.413 & -0.050 & 0.048 & 0.294 & -0.038 & 0.048 & 0.424 \\
\hline Precentral & 0.056 & 0.047 & 0.238 & 0.034 & 0.048 & 0.474 & 0.057 & 0.048 & 0.235 & 0.042 & 0.047 & 0.377 & 0.047 & 0.047 & 0.327 \\
\hline Postcentral & 0.094 & 0.048 & 0.051 & 0.070 & 0.048 & 0.148 & 0.091 & 0.049 & 0.065 & 0.090 & 0.048 & 0.060 & 0.100 & 0.048 & $0.038^{\star}$ \\
\hline Paracentral & 0.087 & 0.048 & 0.072 & 0.054 & 0.049 & 0.265 & 0.069 & 0.049 & 0.158 & 0.055 & 0.048 & 0.253 & 0.056 & 0.049 & 0.249 \\
\hline Precuneus & 0.022 & 0.046 & 0.639 & 0.008 & 0.046 & 0.870 & 0.013 & 0.047 & 0.774 & 0.011 & 0.046 & 0.812 & 0.009 & 0.046 & 0.852 \\
\hline Superior parietal & 0.038 & 0.047 & 0.424 & 0.033 & 0.047 & 0.487 & 0.039 & 0.048 & 0.413 & 0.028 & 0.047 & 0.550 & 0.030 & 0.047 & 0.533 \\
\hline Inferior parietal & 0.039 & 0.045 & 0.385 & 0.028 & 0.045 & 0.533 & 0.060 & 0.045 & 0.187 & 0.043 & 0.045 & 0.341 & 0.041 & 0.045 & 0.362 \\
\hline Supramarginal & 0.074 & 0.046 & 0.110 & 0.040 & 0.047 & 0.395 & 0.083 & 0.047 & 0.078 & 0.088 & 0.046 & 0.058 & 0.091 & 0.046 & 0.050 \\
\hline Insula & 0.004 & 0.051 & 0.937 & -0.016 & 0.051 & 0.753 & 0.019 & 0.052 & 0.711 & -0.021 & 0.051 & 0.685 & -0.017 & 0.051 & 0.737 \\
\hline STG & 0.101 & 0.050 & $0.042^{\star}$ & 0.108 & 0.050 & $0.032^{\star}$ & 0.107 & 0.051 & $0.035^{\star}$ & 0.085 & 0.050 & 0.090 & 0.087 & 0.050 & 0.085 \\
\hline MTG & 0.043 & 0.049 & 0.371 & 0.081 & 0.049 & 0.100 & 0.091 & 0.050 & 0.066 & 0.075 & 0.049 & 0.125 & 0.078 & 0.049 & 0.111 \\
\hline ITG & 0.007 & 0.053 & 0.896 & 0.009 & 0.053 & 0.869 & 0.033 & 0.054 & 0.541 & 0.007 & 0.053 & 0.899 & 0.000 & 0.053 & $>0.999$ \\
\hline Fusiform & -0.020 & 0.054 & 0.706 & -0.030 & 0.054 & 0.575 & -0.009 & 0.055 & 0.874 & -0.027 & 0.055 & 0.628 & -0.025 & 0.055 & 0.645 \\
\hline Entorhinal & 0.070 & 0.057 & 0.218 & 0.096 & 0.058 & 0.097 & 0.125 & 0.058 & $0.032^{\star}$ & 0.120 & 0.057 & $0.037^{\star}$ & 0.120 & 0.057 & $0.037^{\star}$ \\
\hline Parahippocampal & -0.083 & 0.051 & 0.105 & -0.048 & 0.052 & 0.354 & -0.009 & 0.052 & 0.864 & 0.013 & 0.052 & 0.794 & 0.014 & 0.052 & 0.785 \\
\hline Temporal pole & -0.005 & 0.050 & 0.922 & 0.056 & 0.050 & 0.268 & 0.076 & 0.051 & 0.135 & 0.081 & 0.050 & 0.106 & 0.075 & 0.050 & 0.133 \\
\hline Lateral occipital & -0.004 & 0.046 & 0.925 & -0.006 & 0.047 & 0.895 & 0.012 & 0.047 & 0.802 & -0.008 & 0.047 & 0.861 & -0.009 & 0.047 & 0.850 \\
\hline Medial occipital & -0.027 & 0.048 & 0.577 & -0.048 & 0.049 & 0.327 & -0.028 & 0.049 & 0.573 & -0.023 & 0.048 & 0.634 & -0.020 & 0.049 & 0.673 \\
\hline
\end{tabular}

SCZ, schizophrenia; PRS, polygenic risk score; MDD, major depressive disorder; PFC, prefrontal cortex; MFG, middle frontal gyrus; IFG, inferior frontal gyrus; OFC, orbitofrontal cortex; ACC, anterior cingulate cortex; STG, superior temporal gyrus; MTG, middle temporal gyrus; ITG inferior temporal gyjus,

Reported results are for interactive effects between SCZ PRS and MDD status on regional mean cortical thickness, controlling covariates.

$\star_{* \star \star}$ and ${ }^{\star \star \star}$ represent significant results at $p<0.05, p<0.01$ and $p<0.001$, respectively, before correcting for multiple comparisons. Significant results after FDR correction are highlighted in bold. 

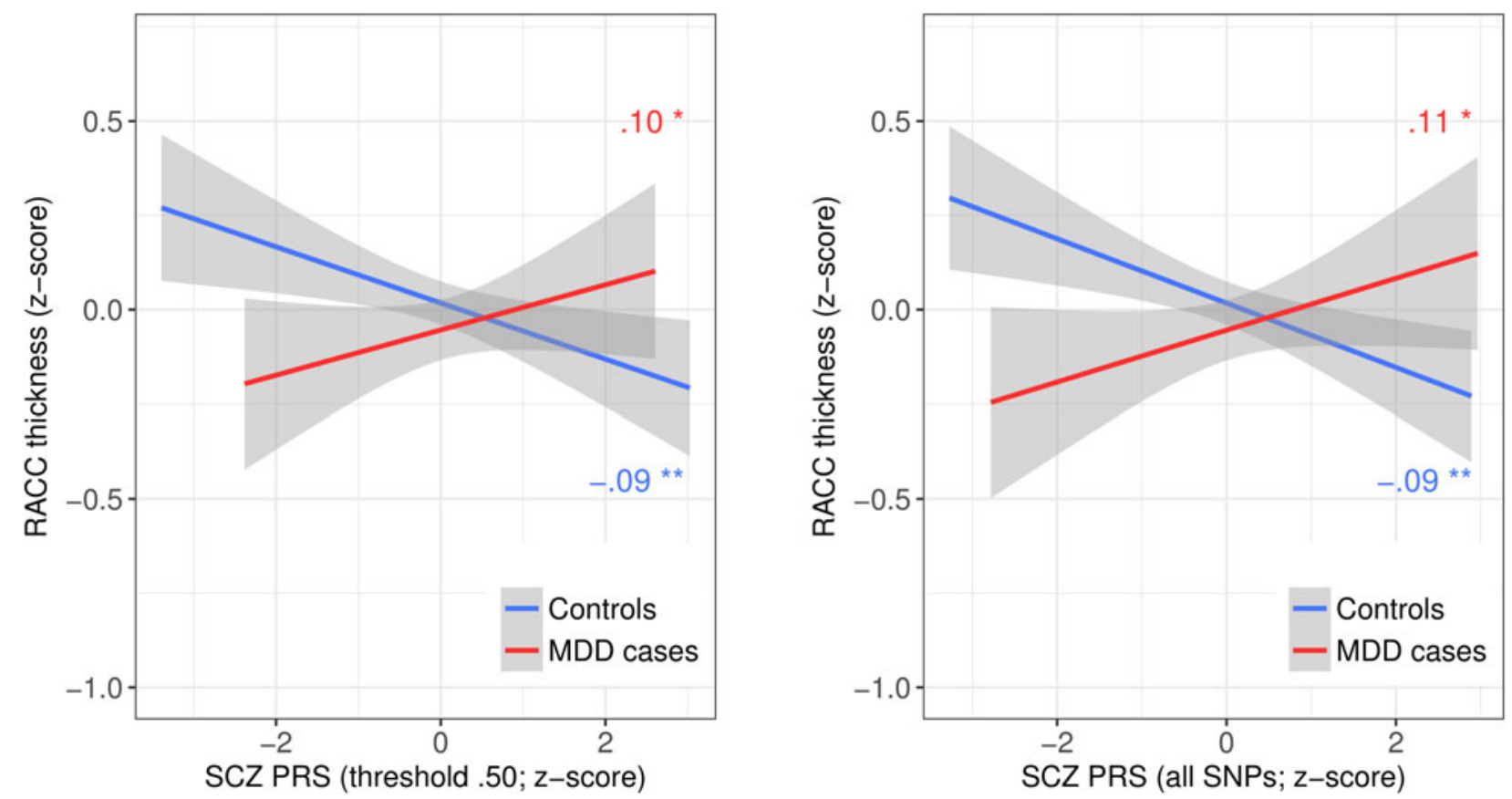

Fig. 2. Mean thickness by SCZ PRS and MDD group for the two significant SCZ PRS by MDD interactions in rostral anterior cingulate cortex. SCZ, schizophrenia; PRS, polygenic risk score; MDD, major depressive disorder; RACC, rostral anterior cingulate cortex. Lines represent least-squares regression lines (red/darker grey = MDD cases; blue/lighter grey = controls); shaded areas represent 95\% confidence intervals. Plots illustrate the two significant interactions between SCZ PRS at threshold 0.5 (left) or including all SNPs (right), and MDD status on RACC mean thickness.

effects between SCZ PRS and MDD on the FA of any of the white matter tracts at any of the PRS thresholds (online Supplementary Table S4). For MD, there was a significant interactive effect of $\beta=0.057(p=0.045)$ at threshold 0.50 and $\beta=0.061 \quad(p=0.033)$ with all SNPs in the uncinate fasciculus (online Supplementary Table S5). Uncinate MD also showed weak and non-significant opposite effects of SCZ PRS in MDD cases $(\beta=0.037 ; \beta=0.035)$ and controls $(\beta=-0.024$; $\beta=-0.030)$. No results survived correction for multiple comparisons.

\section{Discussion}

Following on from findings that MDD differs behaviourally as a function of genetic risk for SCZ, we tested interactions between SCZ PRS and MDD status on a range of brain structure measures in a large sample of UK Biobank participants. Interactions were not significant for most brain measures, but results for rostral ACC mean thickness at two PRS thresholds remained significant after correction for multiple comparisons. In rostral ACC, greater SCZ PRS showed a weak association with thinner cortex among controls, but a weak association with thicker cortex among MDD cases. However, MDD cases and controls only completely diverged toward the lower end of the range in SCZ PRS, where cases still showed thinner rostral ACC. We were able to replicate this interaction in a second subsample, although the effect was attenuated. This significant result seems to indicate localised reserve or protection against the negative neurostructural effects of SCZ-associated genes among individuals with MDD, but alternative explanations are discussed below.

We focused on interactions between SCZ PRS and MDD, but also tested main effects of SCZ PRS within MDD case and control groups for significant interactions. For controls, results suggested that a higher SCZ PRS was associated with reductions in rostral ACC thickness, as expected. These results are consistent with the reductions in prefrontal volumes seen in SCZ (Ross et al., 2006; Keshavan et al., 2008), and therefore with previous evidence of schizophrenia-like neuromorphology among high-risk but healthy controls (Lawrie et al., 2001; Boos et al., 2007). Further, case-control $t$ tests clearly showed deficits in rostral ACC thickness among MDD cases with a low SCZ PRS, compared to low-SCZ-risk controls. This is also expected and consistent with previous evidence of reduced cingulate grey matter (Salvadore et al., 2011; Rodriguez-Cano et al., 2014; Schmaal et al., 2017) in MDD. However, others have observed increased thickness of rostral ACC in MDD (Ancelin et al., 2019) and of other cortical regions in SCZ (Dukart et al., 2017), which does correspond to our findings among individuals at higher genetic risk of SCZ.

Increased rostral ACC thickness among individuals with both MDD and a high genetic predisposition to SCZ may initially seem counterintuitive, suggesting that two putative neuropathologies instead confer benefits when combined. However, while positive associations between SCZ PRS and brain measures among individuals with MDD also stand in contrast with most previous findings (as above), some previous findings are comparable. For example, Papmeyer et al. (2015) reported thickening of inferior frontal and precentral cortices among individuals with both MDD and familial risk of bipolar disorder. One possible explanation is that the subset of MDD cases with a higher SCZ PRS in this study included individuals who had not developed SCZ despite a high level of genetic predisposition. These individuals may have had a neurobiological advantage over others at high genetic risk who did develop SCZ, who were not included in the study. Resistance to aberrant neurodevelopmental influences could explain both why high-SCZ-risk MDD cases did not develop SCZ and why they were more comparable to controls than to low-SCZ-risk cases. Or, simply, the greater rostral ACC thickness observed among high-SCZ-risk MDD cases may have protected against more severe psychopathology. However, as only a small 
proportion of individuals develop SCZ - even among those with a higher PRS - their exclusion is unlikely to have had such an impact on our results.

Alternatively, it may be that the increase in rostral ACC thickness that we observed does not actually represent a benefit. Increased thickness and functional connectivity of rostral ACC have been associated with insomnia (Winkelman et al., 2013) and delusions in SCZ (Schott et al., 2015), respectively. Such symptoms may relate to a deficit in, for example, normal axonal pruning, as this could lead to increased cortical thickness. Some theories of SCZ associate the disorder with altered pruning throughout development (Feinberg, 1982; Keshavan et al., 1994; Glausier and Lewis, 2013), although they typically attribute it to excessive pruning, rather than decreased pruning. However, disruption of normal neurodevelopmental mechanisms could lead to excessive pruning in some areas but decreased pruning in others. While this could in turn lead to greater cortical thickness, these increases might be associated with aberrant hyperactivity or reduced efficiency, contributing to psychiatric symptoms. Further results do suggest SCZ-related increases in thickness and volume of specific brain regions, such as superior parietal cortex and the amygdala (Spoletini et al., 2011; van Haren et al., 2011), supporting this account. Increases in ACC thickness have also been observed with ageing in some studies (Salat et al., 2004; Abe et al., 2008). Whether our results relate to a benefit or impairment specifically among high-SCZ-risk MDD cases, they provide some evidence of an SCZ-risk-related MDD subtype distinct in terms of prefrontal morphology.

Considering that MDD cases and controls only completely diverged at the lower end of the SCZ PRS scale, it may be that case-control differences in rostral ACC thickness were not reversed at the higher end of the range in SCZ PRS, but merely attenuated. In this case, the results relate more directly to Whalley et al.'s (2016) findings of attenuated case-control differences in neuroticism and psychological distress at higher SCZ PRS. This rekindles the idea that both sets of findings represent a protective effect of genetic risk for SCZ among MDD cases, and although it remains unclear why SCZ risk might be protective, the correspondence between clinical and neuroimaging findings strengthens evidence for a possible SCZ-risk-related MDD subtype. Although our cluster analyses were not able to distinguish this subtype, it warrants further investigation.

For most other structural brain metrics assessed, however, we found no significant influence of SCZ PRS on MDD case-control differences. This may have been due to limitations of the study. We used data from UK Biobank, which recruited large numbers of participants from the general population, but our sample (and particularly the smaller subset with data on cortical metrics) may not have been large enough to detect subtle genetic effects. The generalizability of results from UK Biobank is also still potentially limited by selection bias (Allen et al., 2012), as the sample is healthier overall than the general population (Fry et al., 2017). This is a common limitation to most observational studies but, as Fry et al. argue, results are likely to be both robust and widely generalizable. However, a limitation of recruiting from the general population is that SCZ PRS may not have been particularly high for any of our subjects. We still found significant heterogeneity in MDD related to SCZ PRS despite this, which perhaps lends further weight to the conclusion drawn from our significant results for rostral ACC thickness. Investigation of similar effects in a sample including a group of individuals with a higher PRS for SCZ (e.g. relatives of patients) may reveal more about the potential SCZ-risk-related MDD subtype.
UK Biobank participants are also older than the general population, with an average age of over 60 years, although a range of age groups from middle to late adulthood are represented. Focusing on this age group did, however, make it unlikely that subjects were yet to be diagnosed with SCZ, meaning that our results do relate to the effects of genetic risk only, rather than to SCZ itself. Another possible limitation was our measure of MDD, as it was derived from a web-based questionnaire. However, the online CIDI-SF was the most reliable method that could be efficiently used in such a large sample, and provided clinically relevant information based on DSM-IV diagnostic criteria. Finally, there were a number of potential covariates that we were unable to include, as complete data were unavailable at the time of analysis, for example, subjects' use of alcohol, tobacco, other drugs and medications, age of disorder onset and disorder severity. This should be considered when interpreting the current findings.

In summary, we tested for the presence of a distinct subtype of MDD associated with high genetic risk for SCZ by exploring interactive effects between these two variables on structural measures across the brain. Results were generally not significant, but we did observe a significant interactive effect on cortical thickness in rostral ACC for two PRS thresholds, which we were also able to replicate in a second subsample. While the direction of this interaction was unexpected, our results indicate that differences between MDD cases and controls in rostral ACC thickness are significantly influenced by SCZ PRS. This finding, together with related previous findings, suggest subtle differences in MDD related to SCZ risk and rostral ACC, which could influence important factors such as development of the disorder and response to treatment.

Supplementary material. The supplementary material for this article can be found at https://doi.org/10.1017/S003329171900165X.

Acknowledgements. This study was supported by a Wellcome Trust Strategic Award, 'Stratifying Resilience and Depression Longitudinally' (STRADL; ref. 104036/Z/14/Z) and conducted using the UK Biobank Resource (application no. 4844). We would like to thank UK Biobank participants and researchers for their contributions to the study. Part of the work was undertaken at The Centre for Cognitive Ageing and Cognitive Epidemiology (CCACE), part of the cross-council Lifelong Health and Wellbeing Initiative (MR/K026992/1); funding from the Medical Research Council (MRC) and Biotechnology and Biological Sciences Research Council (BBSRC) is gratefully acknowledged. Age UK also provided support for the work undertaken at CCACE (via the Disconnected Mind project). We would also like to acknowledge David Liewald of CCACE for his part in processing imaging data. MAH is supported by The Dr Mortimer and Theresa Sackler Foundation. SRC is supported by the MRC (grants MR/M013111/1 and MR/R024065/1) and the National Institutes of Health (R01AG054628). HCW is supported by a John, Margaret, Alfred and Stewart (JMAS) Sim fellowship from the Royal College of Physicians of Edinburgh (RCPE), and an Edinburgh Scientific Academic Track (ESAT) fellowship from the University of Edinburgh.

Conflict of interest. In the past three years, SML has received research grant support from Janssen, Lundbeck and Sunovion, as well as personal fees from Otsuka, Sunovion and Janssen. AMM has previously received grant support from Pfizer, Lilly and Janssen. None of these funding sources are connected to the current study. MAH is funded by the Dr Mortimer and Theresa Sackler Foundation. Remaining authors have no biomedical financial interests or potential conflicts of interest to declare.

\section{References}

Abdellaoui A, Hugh-Jones D, Kemper KE, Holtz Y, Nivard MG, Veul L, Yengo L, Zietsch BP, Frayling TM, Wray N, Yang J, Verweij KJH and 
Visscher PM (2018) Genetic consequences of social stratification in Great Britain. bioRxiv. doi: doi.org/10.1101/457515.

Abe O, Yamasue H, Aoki S, Suga M, Yamada H, Kasai K, Masutani Y, Kato N, Kato N and Ohtomo K (2008) Aging in the CNS: comparison of gray/white matter volume and diffusion tensor data. Neurobiology of Aging 29, 102-116.

Alfaro-Almagro F, Jenkinson M, Bangerter NK, Andersson JLR, Griffanti L, Douaud G, Sotiropoulos SN, Jbabdi S, Hernandez-Fernandez $M$, Vallee $E$, Vidaurre $D$, Webster $M$, McCarthy P, Rorden C, Daducci A, Alexander DC, Zhang H, Dragonu I, Matthews PM, Miller KL and Smith SM (2018) Image processing and quality control for the first 10000 brain imaging datsets from UK Biobank. Neuroimage 166, 400-424.

Allen N, Sudlow C, Downey P, Peakman T, Danesh J, Elliot P, Gallacher J, Green J, Matthews P, Pell J, Sprosen T, Collins R and UK Biobank (2012). UK biobank: current status and what it means for epidemiology. Health Policy and Technology 1, 123-126.

Ancelin M-L, Carrière I, Artero S, Maller J, Meslin C, Ritchie K, Ryan J and Chaudieu I (2019) Lifetime major depression and grey matter volume. Journal of Psychiatry and Neuroscience 44, 45-53.

Baumeister H and Parker G (2012) Meta-review of depressive subtyping models. Journal of Affective Disorders 139, 126-140.

Behrens TE, Berg HJ, Jbadi S, Rushworth MF and Woolrich MW (2007) Probabilistic diffusion tractography with multiple fibre orientations: What can we gain? Neuroimage 34, 144-155.

Bessette KL, Nave AM, Caprihan A and Stevens MC (2014) White matter abnormalities in adolescents with major depressive disorder. Brain Imaging and Behavior 8, 531-541.

Boos HBM, Aleman A, Cahn W, Hulshoff Pol H and Kahn RS (2007) Brain volumes in relatives of patients with schizophrenia: a meta-analysis. Archives of General Psychiatry 64, 297-304.

Clark DL, Konduru N, Kemp A, Bray S, Brown EC, Goodyear B and Ramasubbu R (2018) The impact of age of onset on amygdala intrinsic connectivity in major depression. Neuropsychiatric Disease and Treatment 14, 343-352.

Cole J, Chaddock CA, Farmer AE, Aitchison KJ, Simmons A, McGuffin P and Fu HC (2012) White matter abnormalities and illness severity in major depressive disorder. British Journal of Psychiatry 201, 33-39.

Cross-Disorder Group of the Psychiatric Genomics Consortium, Lee SH, Ripke S, Neale BM, Faraone SV, Purcell SM, Perlis RH, Mowry BJ, Thapar A, Goddard ME, Witte JS, Absher D, Agartz I, Akil H, Amin F, Andreassen OA, Anjorin A, Anney R, Anttila V, Arking DE, Asherson P, Azevedo MH, Backlund L, Badner JA, Bailey AJ, Banaschewski T, Barchas JD, Barnes MR, Barrett TB, Bass N, Battaglia A, Bauer M, Bayés M, Bellivier F, Bergen SE, Berrettini W, Betancur C, Bettecken T, Biederman J, Binder EB, Black DW, Blackwood DH, Bloss CS, Boehnke M, Boomsma DI, Breen G, Breuer R, Bruggeman R, Cormican P, Buccola NG, Buitelaar JK, Bunney WE, Buxbaum JD, Byerley WF, Byrne EM, Caesar S, Cahn W, Cantor RM, Casas M, Chakravarti A, Chambert K, Choudhury K, Cichon S, Cloninger CR, Collier DA, Cook EH, Coon H, Cormand B, Corvin A, Coryell WH, Craig DW, Craig IW, Crosbie J, Cuccaro ML, Curtis D, Czamara D, Datta S, Dawson G, Day R, De Geus EJ, Degenhardt F, Djurovic S, Donohoe GJ, Doyle AE, Duan J, Dudbridge F, Duketis E, Ebstein RP, Edenberg HJ, Elia J, Ennis S, Etain B, Fanous A, Farmer AE, Ferrier IN, Flickinger $M$, Fombonne E, Foroud T, Frank J, Franke B, Fraser C, Freedman R, Freimer NB, Freitag CM, Friedl M, Frisén L, Gallagher L, Gejman PV, Georgieva L, Gershon ES, Geschwind DH, Giegling I, Gill M, Gordon SD, Gordon-Smith K, Green EK, Greenwood TA, Grice DE, Gross M, Grozeva D, Guan W, Gurling H, De Haan L, Haines JL, Hakonarson H, Hallmayer J, Hamilton SP, Hamshere ML, Hansen TF, Hartmann AM, Hautzinger M, Heath AC, Henders AK, Herms S, Hickie IB, Hipolito M, Hoefels S, Holmans PA, Holsboer F, Hoogendijk WJ, Hottenga JJ, Hultman CM, Hus V, Ingason A, Ising M, Jamain S, Jones EG, Jones I, Jones L, Tzeng JY, Kähler AK, Kahn RS, Kandaswamy R, Keller MC, Kennedy JL, Kenny E, Kent L, Kim Y, Kirov GK, Klauck SM, Klei L, Knowles JA, Kohli MA, Koller DL, Konte B, Korszun A, Krabbendam L, Krasucki R, Kuntsi J,
Kwan $P$, Landén $M$, Långström $N$, Lathrop $M$, Lawrence $J$, Lawson WB, Leboyer M, Ledbetter DH, Lee PH, Lencz T, Lesch KP, Levinson DF, Lewis CM, Li J, Lichtenstein P, Lieberman JA, Lin DY, Linszen DH, Liu C, Lohoff FW, Loo SK, Lord C, Lowe JK, Lucae S, MacIntyre DJ, Madden PA, Maestrini E, Magnusson PK, Mahon PB, Maier W, Malhotra AK, Mane SM, Martin CL, Martin NG, Mattheisen $M$, Matthews $K$, Mattingsdal $M$, McCarroll SA, McGhee KA, McGough JJ, McGrath PJ, McGuffin P, McInnis MG, McIntosh A, McKinney R, McLean AW, McMahon FJ, McMahon WM, McQuillin A, Medeiros H, Medland SE, Meier S, Melle I, Meng F, Meyer J, Middeldorp CM, Middleton L, Milanova V, Miranda A, Monaco AP, Montgomery GW, Moran JL, Moreno-De-Luca D, Morken G, Morris DW, Morrow EM, Moskvina V, Muglia P, Mühleisen TW, Muir WJ, Müller-Myhsok B, Murtha M, Myers RM, Myin-Germeys I, Neale MC, Nelson SF, Nievergelt CM, Nikolov I, Nimgaonkar V, Nolen WA, Nöthen MM, Nurnberger JI, Nwulia EA, Nyholt DR, O'Dushlaine C, Oades RD, Olincy A, Oliveira G, Olsen L, Ophoff RA, Osby U, Owen MJ, Palotie A, Parr JR, Paterson AD, Pato CN, Pato MT, Penninx BW, Pergadia ML, Pericak-Vance MA, Pickard BS, Pimm J, Piven J, Posthuma D, Potash JB, Poustka F, Propping P, Puri V, Quested DJ, Quinn EM, Ramos-Quiroga JA, Rasmussen HB, Raychaudhuri S, Rehnström K, Reif A, Ribasés M, Rice JP, Rietschel M, Roeder K, Roeyers H, Rossin L, Rothenberger A, Rouleau G, Ruderfer D, Rujescu D, Sanders AR, Sanders SJ, Santangelo SL, Sergeant JA, Schachar R, Schalling M, Schatzberg AF, Scheftner WA, Schellenberg GD, Scherer SW, Schork NJ, Schulze TG, Schumacher J, Schwarz M, Scolnick E, Scott LJ, Shi J, Shilling PD, Shyn SI, Silverman JM, Slager SL, Smalley SL, Smit JH, Smith EN, Sonuga-Barke EJ, St Clair D, State M, Steffens M, Steinhausen HC, Strauss JS, Strohmaier J, Stroup TS, Sutcliffe JS, Szatmari P, Szelinger S, Thirumalai S, Thompson RC, Todorov AA, Tozzi F, Treutlein J, Uhr M, van den Oord EJ, Van Grootheest G, Van Os J, Vicente AM, Vieland VJ, Vincent JB, Visscher PM, Walsh CA, Wassink TH, Watson SJ, Weissman MM, Werge T, Wienker TF, Wijsman EM, Willemsen G, Williams N, Willsey AJ, Witt SH, Xu W, Young AH, Yu TW, Zammit S, Zandi PP, Zhang P, Zitman FG, Zöllner S, Devlin B, Kelsoe JR, Sklar P, Daly MJ, O'Donovan MC, Craddock N, Sullivan PF, Smoller JW, Kendler KS, Wray NR and International Inflammatory Bowel Disease Genetics Consortium (2013) Genetic relationship between five psychiatric disorders estimated from genome-wide SNPs. Nature Genetics 45, 984-994.

Dale AM, Fischl B and Sereno MI (1999) Cortical surface-based analysis. I. Segmentation and surface reconstruction. Neuroimage 9, 179-194.

de Groot M, Vernooij MW, Klein S, Ikram MA, Vos FM, Smith SM, Niessen WJ and Andersson JL (2013) Improving alignment in Tract-based spatial statistics: evaluation and optimization of image registration. Neuroimage 76, 400-411.

Desikan RS, Ségonne F, Fischl B, Quinn BT, Dickerson BC, Blacker D, Buckner RL, Dale AM, Maguire RP, Hyman BT, Albert MS and Killiany RJ (2006) An automated labeling system for subdividing the human cerebral cortex on MRI scans into gyral based regions of interest. Neuroimage 31, 968-980.

Dukart J, Smieskova R, Harrisberger F, Lenz C, Schmidt A, Walter A, Huber C, Riecher-Rössler A, Simon A, Lang UE, Fusar-Poli $P$ and Borgwardt S (2017) Age-related brain structural alterations as an intermediate phenotype of psychosis. Journal of Psychiatry \& Neuroscience 42, 307-319.

Ellison-Wright I and Bullmore E (2009) Meta-analysis of diffusion tensor imaging studies in schizophrenia. Schizophrenia Research 108, 3-10.

Euesden J, Lewis CM and O'Reilly PF (2015) PRSice: Polygenic Risk Score software. Bioinformatics (Oxford, England) 31, 1466-1468.

Fava M, Uebelacker LA, Alpert JE, Nierenberg AA, Pava JA and Rosenbaum JF (1997) Major depressive subtypes and treatment response. Biological Psychiatry 42, 568-576.

Feinberg I (1982) Schizophrenia: caused by a fault in programmed synaptic elimination during adolescence? Journal of Psychiatric Research 17, 319-334.

Fischl B, Sereno MI and Dale AM (1999) Cortical surface-based analysis. II: Inflation, flattening, and a surface-based coordinate system. Neuroimage $\mathbf{9}$, 195-207. 
Fischl B, van der Kouwe A, Destrieux C, Halgren E, Ségonne F, Salat DH, Busa E, Seidman LJ, Goldstein J, Kennedy D, Caviness V, Makris N, Rosen B and Dale AM (2004) Automatically parcellating the human cerebral cortex. Cerebral Cortex 14, 11-22.

Flint J and Kendler KS (2014) The genetics of major depression. Neuron 81, 484-503.

Fry A, Littlejohns TJ, Sudlow C, Doherty N, Adamska L, Sprosen T, Collins R and Allen NE (2017) Comparison of sociodemographic and health-related characteristics of UK Biobank participants with those of the general population. American Journal of Epidemiology 186, 1026-1034.

Gallo JJ and Rabins PV (1999) Depression without sadness: alternative presentations of depression in late life. American Family Physician 60, $820-826$.

Glausier JR and Lewis DA (2013) Dendritic spine pathology in schizophrenia. Neuroscience 251, 90-107.

Hagenaars SP, Harris SE, Davies G, Hill WD, Liewald DC, Ritchie SJ, Marioni RE, Fawns-Ritchie C, Cullen B, Malik R, METASTROKE Consortium, International Consortium for Blood Pressure GWAS, SpiroMeta Consortium, CHARGE Consortium Pulmonary Group, CHARGE Consortium Aging and Longevity Group, Worrall BB, Sudlow CL, Wardlaw JM, Gallacher J, Pell J, McIntosh AM, Smith DJ, Gale CR and Deary IJ (2016). Shared genetic aetiology between cognitive functions and physical and mental health in UK Biobank $(\mathrm{N}=112151)$ and 24 GWAS consortia. Molecular Psychiatry 21, 1624-1632.

Hasler G, Drevets WC, Manji HK and Charney DS (2004) Discovering endophenotypes for major depression. Neuropsychopharmacology 29, 1765-1781

Henning C (2015) fpc: Flexible Procedures for Clustering. R package version 2.1-10. Howard DM, Clarke TK, Adams MJ, Hafferty JD, Wigmore EM, Zeng Y, Hall LS, Gibson J, Boutin TS, Hayward C, Thomson PA, Porteous DJ, Smith BH, Murray AD, Major Depressive Disorder Working Group of the Psychiatric GWAS Consortium, Haley CS, Deary IJ, Whalley HC and McIntosh AM (2017). The stratification of major depressive disorder into genetic subgroups. bioRxiv. doi: doi.org/10.1101/134601

Howard DM, Adams MJ, Clarke TK, Hafferty JD, Gibson J, Shirali M, Coleman JRI, Hagenaars SP, Ward J, Wigmore EM, Alloza C, Shen X, Barbu MC, Xu EY, Whalley HC, Marioni RE, Porteous DJ, Davies G, Deary IJ, Hemani G, Berger K, Teismann H, Rawal R, Arolt V, Baune BT, Dannlowski U, Domschke K, Tian C, Hinds DA, 23andMe Research Team, Major Depressive Disorder Working Group of the Psychiatric Genomics Consortium, Trzaskowski M, Byrne EM, Ripke S, Smith DJ, Sullivan PF, Wray NR, Breen G, Lewis CM and McIntosh AM (2019). Genome-wide meta-analysis of depression identifies 102 independent variants and highlights the importance of prefrontal brain regions. Nature Neuroscience 22, 343-352.

Jaworska N, MacMaster FP, Gaxiola I, Cortese F, Goodyear B and Ramasubbu R (2014) A preliminary study of the age of onset and childhood trauma on cortical thickness in major depressive disorder. BioMed Research International 2014, 410472.

Kennedy SH (2008) Core symptoms of major depressive disorder: relevance to diagnosis and treatment. Dialogues in Clinical Neuroscience 10, 271-277.

Keshavan MS, Anderson S and Pettegrew JW (1994) Is schizophrenia due to excessive synaptic pruning in the prefrontal cortex? The Feinberg hypothesis revisited. Journal of Psychiatric Research 28, 239-265.

Keshavan MS, Tandon R, Boutros NN and Nasrallah HA (2008) Schizophrenia, "just the facts": what we know in 2008 Part 3: neurobiology. Schizophrenia Research 106, 89-107.

Kessler RC, Andrews G, Mroczek D, Ustun B and Wittchen H-U (1998) The World Health Organization Composite International Diagnostic interview short-form (CIDI-SF). International Journal of Methods in Psychiatric Research 7, 171-185.

Kim MJ, Hamilton JP and Gotlib IH (2008) Reduced caudate gray matter volume in women with major depressive disorder. Psychiatry Research 164, 114-122.

Kroenke K, Spitzer RL and Williams JB (2001) The PHQ-9: validity of a brief depression severity measure. Journal of General Internal Medicine 16, 606-613.

Lawrie SM, Whalley HC, Abukmeil SS, Kestelman JN, Donnelly L, Miller P, Best JJ, Owens DG and Johnstone EC (2001) Brain structure, genetic liability, and psychotic symptoms in subjects at high risk of developing schizophrenia. Biological Psychiatry 49, 811-823.

Lu Y, Liang H, Han D, Mo Y, Li Z, Cheng Y, Xu X, Shen Z, Tan C, Zhao W, Zhu Y and Sun X (2016) The volumetric and shape changes of the putamen and thalamus in first episode, untreated major depressive disorder. Neuroimage Clinical 11, 658-666.

MacMaster FP, Mirza Y, Szeszko PR, Kmiecik LE, Easter PC, Taormina SP, Lynch M, Rose M, Moore GJ and Rosenberg DR (2008) Amygdala and hippocampal volumes in familial early onset major depressive disorder. Biological Psychiatry 63, 385-390.

Milaneschi Y, Lamers F, Peyrot WJ, Baune BT, Breen G, Dehghan A, Forstner AJ, Grabe HJ, Homuth G, Kan C, Lewis C, Mullins N, Nauck M, Pistis G, Preisig M, Rivera M, Rietschel M, Streit F, Strohmaier J, Teumer A, Van der Auwera S, Wray NR, Boomsma DI, Penninx BWJH and CHARGE Inflammation Working Group and the Major Depressive Disorder Working Group of the Psychiatric Genomics Consortium (2017) Genetic association of major depression with atypical features and obesity-related immunometabolic dysregulations. JAMA Psychiatry 74, 1214-1225.

Miller KL, Alfaro-Almagro F, Bangerter NK, Thomas DL, Yacoub E, Xu J, Bartsch AJ, Jbabdi S, Sotiropoulos SN, Andersson JL, Griffanti L, Douaud G, Okell TW, Weale P, Dragonu I, Garratt S, Hudson S, Collins R, Jenkinson M, Matthews PM and Smith SM (2016) Multimodal population brain imaging in the UK biobank prospective epidemiological study. Nature Neuroscience 19, 1523-1536.

Murdoch D and Chow ED (2013) ellipse: Functions for drawing ellipses and ellipse-like confidence regions. $\mathrm{R}$ package version 0.3-8.

Papmeyer M, Giles S, Sussmann JE, Kielty S, Stewart T, Lawrie SM, Whalley HC and McIntosh AM (2015) Cortical thickness in individuals at high familial risk of mood disorders as they develop major depressive disorder. Biological Psychiatry 78, 58-66.

Patenaude B, Smith SM, Kennedy DN and Jenkinson M (2011) A Bayesian model of shape and appearance for subcortical brain segmentation. Neuroimage 56, 907-922.

Power RA, Tansey KE, Buttenschøn HN, Cohen-Woods S, Bigdeli T, Hall LS, Kutalik Z, Lee SH, Ripke S, Steinberg S, Teumer A, Viktorin A, Wray NR, Arolt V, Baune BT, Boomsma DI, Børglum AD, Byrne EM, Castelao E, Craddock N, Craig IW, Dannlowski U, Deary IJ, Degenhardt F, Forstner AJ, Gordon SD, Grabe HJ, Grove J, Hamilton SP, Hayward C, Heath AC, Hocking LJ, Homuth G, Hottenga JJ, Kloiber S, Krogh J, Landén M, Lang M, Levinson DF, Lichtenstein P, Lucae S, MacIntyre DJ, Madden P, Magnusson PKE, Martin NG, McIntosh AM, Middeldorp CM, Milaneschi Y, Montgomery GW, Mors O, Müller-Myhsok B, Nyholt DR, Oskarsson H, Owen MJ, Padmanabhan S, Penninx BWJH, Pergadia ML, Porteous DJ, Potash JB, Preisig M, Rivera M, Shi J, Shyn SI, Sigurdsson E, Smit JH, Smith BH, Stefansson H, Stefansson K, Strohmaier J, Sullivan PF, Thomson P, Thorgeirsson TE, Van der Auwera S, Weissman MM, CONVERGE Consortium, CARDIoGRAM Consortium, GERAD1 Consortium, Breen G and Lewis CM (2017) Genome-wide association for major depression through age at onset stratification: Major Depressive Disorder Working Group of the Psychiatric Genetics Consortium. Biological Psychiatry 81, 325-335.

R Core Team (2013) R: A Language and Environment for Statistical Computing. Vienna: R Foundation for Statistical Computing.

Ripke S, Wray NR, Lewis CM, Hamilton SP, Weissman MM, Breen G, Byrne EM, Blackwood DH, Boomsma DI, Cichon S, Heath AC, Holsboer F, Lucae S, Madden PA, Martin NG, McGuffin P, Muglia P, Noethen MM, Penninx BP, Pergadia ML, Potash JB, Rietschel M, Lin D, Müller-Myhsok B, Shi J, Steinberg S, Grabe HJ, Lichtenstein P, Magnusson P, Perlis RH, Preisig M, Smoller JW, Stefansson K, Uher R, Kutalik Z, Tansey KE, Teumer A, Viktorin A, Barnes MR, Bettecken T, Binder EB, Breuer R, Castro VM, Churchill SE, Coryell WH, Craddock N, Craig IW, Czamara D, De Geus EJ, Degenhardt F, Farmer AE, Fava M, Frank J, Gainer VS, Gallagher PJ, Gordon SD, Goryachev S, Gross M, Guipponi M, Henders AK, Herms S, Hickie IB, Hoefels S, Hoogendijk W, Hottenga J, Iosifescu DV, Ising M, Jones I, 
Jones L, Jung-Ying T, Knowles JA, Kohane IS, Kohli MA, Korszun A, Landen M, Lawson WB, Lewis G, Macintyre D, Maier W, Mattheisen M, McGrath PJ, McIntosh A, McLean A, Middeldorp CM, Middleton L, Montgomery GM, Murphy SN, Nauck M, Nolen WA, Nyholt DR, O'Donovan M, Oskarsson H, Pedersen N, Scheftner WA, Schulz A, Schulze TG, Shyn SI, Sigurdsson E, Slager SL, Smit JH, Stefansson H, Steffens M, Thorgeirsson T, Tozzi F, Treutlein J, Uhr M, van den Oord EJ, Van Grootheest G, Völzke H, Weilburg JB, Willemsen G, Zitman FG, Neale B, Daly M, Levinson DF and Sullivan PF (2013) A mega-analysis of genome-wide association studies for major depressive disorder. Molecular Psychiatry 18, 497-511.

Rodríguez-Cano E, Sarró S, Monté GC, Maristany T, Salvador R, McKenna PJ and Pomarol-Clotet E (2014) Evidence for structural and functional abnormality in the subgenual anterior cingulate cortex in major depressive disorder. Psychological Medicine 44, 3263-3273.

Ross CA, Margolis RL, Reading SA, Pletnikov M and Coyle JT (2006) Neurobiology of schizophrenia. Neuron 52, 139-153.

Salat DH, Buckner RL, Snyder AZ, Greve DN, Desikan RS, Busa E, Morris JC, Dale AM and Fischl B (2004) Thinning of the cerebral cortex in aging. Cerebral Cortex 14, 721-730.

Salvadore G, Nugent AC, Lemaitre H, Luckenbaugh DA, Tinsley R, Cannon DM, Neumeister A, Zarate Jr CA and Drevets WC (2011). Prefrontal cortical abnormalities in currently depressed versus currently remitted patients with major depressive disorder. Neuroimage 54, 2643-2651.

Schizophrenia Working Group of the Psychiatric Genetics Consortium (2014) Biological Insights from the 108 schizophrenia-associated genetic loci. Nature 511, 421-427.

Schmaal L, Veltman DJ, van Erp TG, Sämann PG, Frodl T, Jahanshad N, Loehrer E, Tiemeier H, Hofman A, Niessen WJ, Vernooij MW, Ikram MA, Wittfeld K, Grabe HJ, Block A, Hegenscheid K, Völzke H, Hoehn D, Czisch M, Lagopoulos J, Hatton SN, Hickie IB, Goya-Maldonado R, Krämer B, Gruber $O$, Couvy-Duchesne B, Rentería ME, Strike LT, Mills NT, de Zubicaray GI, McMahon KL, Medland SE, Martin NG, Gillespie NA, Wright MJ, Hall GB, MacQueen GM, Frey EM, Carballedo A, van Velzen LS, van Tol MJ, van der Wee NJ, Veer IM, Walter H, Schnell K, Schramm E, Normann C, Schoepf D, Konrad C, Zurowski B, Nickson T, McIntosh AM, Papmeyer M, Whalley HC, Sussmann JE, Godlewska BR, Cowen PJ, Fischer FH, Rose M, Penninx BW, Thompson PM and Hibar DP (2016) Subcortical brain alterations in major depressive disorder: findings from the ENIGMA Major Depressive Disorder working group. Molecular Psychiatry 21, 806-812.

Schmaal L, Hibar DP, Sämann PG, Hall GB, Baune BT, Jahanshad N, Cheung JW, van Erp TGM, Bos D, Ikram MA, Vernooij MW, Niessen WJ, Tiemeier H, Hofman A, Wittfeld K, Grabe HJ, Janowitz $D$, Bülow $R$, Selonke $M$, Völzke $H$, Grotegerd $D$, Dannlowski U, Arolt V, Opel N, Heindel W, Kugel H, Hoehn D, Czisch M, Couvy-Duchesne B, Rentería ME, Strike LT, Wright MJ, Mills NT, de Zubicaray GI, McMahon KL, Medland SE, Martin NG, Gillespie NA, Goya-Maldonado R, Gruber O, Krämer B, Hatton SN, Lagopoulos J, Hickie IB, Frodl T, Carballedo A, Frey EM, van Velzen LS, Penninx BWJH, van Tol MJ, van der Wee NJ, Davey CG, Harrison BJ, Mwangi B, Cao B, Soares JC, Veer IM, Walter H, Schoepf D, Zurowski B, Konrad C, Schramm E, Normann C, Schnell K, Sacchet MD, Gotlib IH, MacQueen GM, Godlewska BR, Nickson T, McIntosh AM, Papmeyer M, Whalley HC, Hall J, Sussmann JE, Li M, Walter M, Aftanas L, Brack I, Bokhan NA, Thompson PM and Veltman DJ (2017) Cortical abnormalities in adults and adolescents with major depression based on brain scans from 20 cohorts worldwide in the ENIGMA Major Depressive Disorder Working Group. Molecular Psychiatry 22, 900-909.

Schott BH, Voss M, Wagner B, Wüstenberg T, Düzel E and Behr J (2015) Fronto-limbic novelty processing in acute psychosis: disrupted relationship with memory performance and potential implications for delusions. Frontiers in Behavioral Neuroscience 9, 144.

Schulze TG, Akula N, Breuer R, Steele J, Nalls MA, Singleton AB, Degenhardt FA, Nöthen MM, Cichon S, Rietschel M, Bipolar Genome Study and McMahon FJ (2014). Molecular genetic overlap in bipolar disorder, schizophrenia, and major depressive disorder. World Journal of Biological Psychiatry 15, 200-208.

Shen X, Reus LM, Cox SR, Adams MJ, Liewald DC, Bastin ME, Smith DJ, Deary IJ, Whalley HC and McIntosh AM (2017) Subcortical volume and white matter integrity abnormalities in major depressive disorder: findings from UK Biobank imaging data. Scientific Reports 7, 5547.

Spoletini I, Piras F, Fagioli S, Rubino IA, Martinotti G, Siracusano A, Caltagirone C and Spalletta G (2011) Suicidal attempts and increased right amygdala volume in schizophrenia. Schizophrenia Research 125, 30-40. Sullivan PF, Neale MC and Kendler KS (2000) Genetic epidemiology of major depression: review and meta-analysis. American Journal of Psychiatry 157, 1552-1562.

van Haren NEM, Schnack HG, Cahn W, van den Heuvel MP, Lepage C and Collins L (2011) Changes in cortical thickness during the course of illness in schizophrenia. Archives of General Psychiatry 68, 871-880.

van Loo HM, Cai T, Gruber MJ, Li J, de Jonge P, Petukhova M, Rose S, Sampson NA, Schoevers RA, Wardenaar KJ, Wilcox MA, Al-Hamzawi AO, Andrade LH, Bromet EJ, Bunting B, Fayyad J, Florescu SE, Gureje $\mathrm{O}, \mathrm{Hu} \mathrm{C}$, Huang $\mathrm{Y}$, Levinson D, Medina-Mora ME, Nakane Y, Posada-Villa J, Scott KM, Xavier M, Zarkov Z and Kessler RC (2014) Major depressive disorder subtypes to predict long-term course. Depression and Anxiety 31, 765-777.

Wain LV, Shrine N, Miller S, Jackson VE, Ntalla I, Soler Artigas M, Billington CK, Kheirallah AK, Allen R, Cook JP, Probert K, Obeidat M, Bossé Y, Hao K, Postma DS, Paré PD, Ramasamy A, UK Brain Expression Consortium, Mägi R, Mihailov E, Reinmaa E, Melén E, O'Connell J, Frangou E, Delaneau O, OxGSK Consortium, Freeman C, Petkova D, McCarthy M, Sayers I, Deloukas P, Hubbard R, Pavord I, Hansell AL, Thomson NC, Zeggini E, Morris AP, Marchini J, Strachan DP, Tobin MD and Hall IP (2015). Novel insights into the genetics of smoking behaviour, lung function, and chronic obstructive pulmonary disease (UK BiLEVE): a genetic association study in UK Biobank. The Lancet Respiratory Medicine 3, 769-781.

Whalley HC, Adams MJ, Hall LS, Clarke T-K, Fernandez-Pujals AM, Gibson J, Wigmore E, Hafferty J, Hagenaars SP, Davies G, Campbell A, Hayward C, Lawrie SM, Porteous DJ, Deary IJ and McIntosh AM (2016) Dissection of major depressive disorder using polygenic risk scores for schizophrenia in two independent cohorts. Translational Psychiatry 6, e938.

Wickham H and Chang W (2016). ggplot2: Create elegant data visualisations using The Grammar of Graphics. R package version 2.2.1.

Winkelman JW, Plante DT, Schoerning L, Benson K, Buxton OM, O'Connor SP, Jensen JE, Renshaw PF and Gonenc A (2013) Increased rostral anterior cingulate cortex volume in chronic primary insomnia. Sleep 36, 991-998.

Wong AH and van Tol HH (2003) Schizophrenia: from phenomenology to neurobiology. Neuroscience and Biobehavioral Reviews 27, 269-306.

Yao L, Lui S, Liao Y, Du MY, Hu N, Thomas JA and Gong QY (2013) White matter deficits in first episode schizophrenia: an activation likelihood estimation meta-analysis. Progress in Neuro-Psychopharmacol and Biological Psychiatry 45, 100-106. 